\title{
AMERICAN AND UKRAINIAN TIME CONCEPTS IN THE CONTEXT OF CROSS-CULTURAL COMMUNICATION
}

\author{
Koliada E. K., Kalynovska I.
}

\section{INTRODUCTION}

Every language has its own perspective while interpreting the reality that manifests itself in miscellaneous activities of life. Misunderstandings are likely to occur between people from different cultures because of time concepts. The concept of time and the words used to define time units differ greatly in many languages, including English and Ukrainian. The aim of this study is to explore the differences between American and Ukrainian time concepts and translation problems caused by them. We will analyse specific words and word combinations referring to the concept of time in English and in Ukrainian, which can present difficulties in translation from one language to another. The relevance of the research lies in the examination of American and Ukrainian linguistic and cultural differences in time perception that can make communication difficult. The data were collected from monolingual dictionaries as they are one of the most important tools for the translator due to their valuable lexical information. The results of the authors' personal observations on translation problems are recorded in the form of written descriptions. In the course of the research, the following methods were used: analysis, synthesis, induction, deduction, the comparative method, description, and interpretation.

\section{Seasons}

In both the English and the Ukrainian languages there are concepts of four seasons of the year. However, the idea of the time of year or the seasons and even the most fundamental level, the order in which they are listed, differ between the two languages. In Ukrainian the seasons are usually listed in the following order: zyma (winter), vesna (spring), lito (summer) and osin (autumn/fall). The seasons are listed in this order because the calendar year begins in winter. In English most often the seasons are listed as follows: spring, summer, autumn/fall and winter. This pattern reflects the concept of life cycle found not only in nature but also in man. Spring is seen as new life and the blossoming of new possibilities and 
opportunities. It is "the first stage and freshest period: the spring of life" (The Random House College Dictionary). Man relates to this in his earliest years when life still holds innocence and discovery, allowing for the development in any number of opportunities. The idiom be no spring chicken means be no longer young. For example: Are you sure he should be playing squash at his age? He's no spring chicken, you know! (Oxford Idioms Dictionary for Learners of English). The colloquial phrase He's no spring chicken refers to the idea that a man has moved beyond his prime. Summer is a word picture that illustrates the time of maturing and continued growth. It is "the period of finest development, perfection, or beauty previous to any decline" (The Random House College Dictionary). In English we refer to the best years of a man's life as the summer of his life. The time that follows summer is autumn/fall, and is seen as a relaxed time and is a slower paced time of year. This concept in a man's life refers to when he is established in his career and personal life allowing for an enjoyment of past achievements. Autumn is a period of maturity or incipient decline such as in the word combination in the autumn of life. Winter in reference to a man's life normally refers to the time after retirement until his death. It is "the last or final period of life" (The Random House College Dictionary). Let us look at each word defining the season in more detail.

Winter. Zyma in Ukrainian encompasses the period falling between the first of December and the last day of February (which is the twenty-ninth in a leap year or the twenty-eighth each year in between). Rather in English winter extends from the December solstice to the March equinox. As the Random House College Dictionary puts it, winter is "the cold season between autumn and spring: in the Northern Hemisphere from the winter solstice to the vernal equinox; in the Southern Hemisphere from the summer solstice to the autumnal equinox (The Random House College Dictionary). The winter solstice occurs yearly around the twenty-second of December but does not have a fixed date. The vernal equinox similarly does not have a fixed date but occurs around the twenty-first of March. It should be noted that as the seasons have no fixed date, therefore once temperatures drop, colloquial speech often refers to that time of year as winter. It is interesting to note that International Women's Day, the eighth of March, which is so popular in Ukraine but not celebrated in the US, would therefore theoretically be considered a winter holiday by some Americans (Kovalskaya \& Ritchey, 2001: 21).

Spring. Vesna in Ukrainian refers to the period of time between the first of March and the thirty-first of May. This is not the case in the English notion of spring, which is defined as "the season between winter and 
summer: in the Northern Hemisphere from the vernal equinox to the summer solstice; in the Southern Hemisphere from the autumnal equinox to the winter solstice" (The Random House College Dictionary). Thus, spring extends from the March equinox till the June solstice, which is approximately from the twenty-first of March till the twenty-second of June. American tradition dictates that Groundhog Dау (День Бабака), the second of February, will forecast that there is to be an early or late spring. On Groundhog Day, when the groundhog emerges from its burrow, should it see its shadow he will return to his burrow to hibernate for six more weeks, and there will be a long winter. If the groundhog emerges and does not see his shadow due to cloudy weather, it is believed that there will be an early spring.

Summer. From the first of June till the thirty first of August is the period of the Ukrainian season, which is called lito. The corresponding English notion of summer officially begins at the summer solstice and ends at the autumnal equinox (The Random House College Dictionary), which approximately encompasses the period of time between the twenty-second of June and the twenty-third of September. It is interesting to note that in this season the use of the word summer normally refers to the time of year in which children have vacation from school. Thus in different parts of the US the concept of summer revolves around children's summer vacations, which differ from school to school, and also around the weather. This makes the concept of summer perhaps even more anthropocentric in nature to its Ukrainian counterpart lito. One example of this is in the word combination summer days. This word combination may refer to either a day in the summer season or a day that occurs in another season taking on one or more characteristics of summer (Kovalskaya \& Ritchey, 2001: 2223). Should this day occur in spring it means that the weather is summer like and lends itself to traditional summer activities such as picnics, or outdoor sports. Should the phrase be used in the concept of autumn/fall then it refers to not only unusually warm weather but also a day that is not as stringent in time orientation. In Ukrainian the corresponding phrase litni $d n i$ can refer to only the days specified within the summer season and may not refer to any other time of year.

Autumn/Fall. Autumn and fall are synonyms to each other and are equivalent to the Ukrainian word osin. While both words are used in American English, autumn is the preferred word in British English. By the Ukrainian calendar autumn begins on the first of September and ends on the thirtieth of November while again in English the dates are officially counted from the autumnal equinox, around the twenty-third of September, until the winter solstice which occurs approximately on the twenty-second 
of December each year (The Random House College Dictionary). It should be noted that in Ukraine the school year begins every year on the first of September, unless the day falls on a Sunday, thus making the concept of osin coordinate easily with the start of school. As noted earlier school starts on different days of the year in the US, depending on the part of the country, spanning from the end of August until the second week in September.

\section{Lengths of Time}

While dealing with the concept of time it is interesting to note that in the two languages there are basic differences in dealing with denoting lengths of time. While the Ukrainian language tends to be limited to one way of denoting a specific length of time, in English there is often a choice. The American practice uses more discrete time units in comparison with the Ukrainian one. For example, in Ukrainian the word combination pivtora roku may be translated into English as a year and a half or eighteen months and similarly pivtora misiatsia may be translated as a month and a half or six weeks and try misiatsi may be referred to as three months or twelve weeks. Preference to which English phrase is used depends on the region of the country in the US, however both phrases are equally acceptable and understandable to native speakers. The Ukrainian notion of pivroku is best translated as six months.

In American English there were traditionally more words to denote a specific time period, however most of these have fallen out of use. For example, the use of the word score in English refers to a twenty year period of time, yet most Americans do not know the specific number of years that a score includes if they are not familiar with president Abraham Lincoln's famous opening line of the Gettysburg Address ("four score and seven years ago our fore fathers ..."). Similarly, the use of the word fortnight has fallen out of use in the US and generally unknown except to those who study British Literature. According to the Random House College Dictionary, fortnight is "the space of fourteen nights and days; two weeks" (The Random House College Dictionary).

Another concept that requires clarification for Ukrainian learners of English is that of weekend. A weekend in English refers to the days of Saturday and Sunday only when denoting time (Oxford Advanced Learner's Dictionary). The word weekend is used regardless of whether the person has the days off from school or work. This should be compared to the Ukrainian word combination vykhidni dni, or the word vykhidni with the primary difference lying in that vykhidni are non-work days that may occur at any time throughout the week and are not confined to only 
Saturday and Sunday. The word combination long weekend is used in English to denote when an extra day vacation or holiday occurs on either side of the weekend, for example a long weekend may be made up of the combination of the days Friday, Saturday and Sunday or the days Saturday, Sunday and Monday, i.e. it is "a holiday/vacation of three or four days from Friday or Saturday to Sunday or Monday" (ibid.).

Doba is the commonly used word in Ukrainian which has no direct translation into English. In Ukrainian it means a period of twenty-four hours, especially from midnight to the following midnight, while in English it may be translated into 24 hours, day, and day and night. Many Ukrainian students find the translation of doba into day inadequate, because the word den in Ukrainian is equivalent to only daylight hours. Another translation of doba is round (around) the clock, however this word combination does not relay the Ukrainian concept of doba properly to an American because normally the word combination round (around) the clock has a very specialized usage meaning shift work (pozminna robota), for example, at a factory, or a store, or a restaurant. It is advisable to translate the word doba into round the clock when dealing with businesses or work done continuously in a twenty-four hour period. In other cases such as travel, criminal detainment and some everyday activities, the translation of doba should be made directly into day.

\section{Times of Day}

Each day is divided into morning, afternoon, evening and night. But the Ukrainian words ranok, den, vechir and nich are not the exact equivalents of the corresponding English concepts. This can be explained by the fact that Ukrainians are more clock-oriented whereas Americans tend to be more nature or activity-oriented. This means that for a Ukrainian person morning (that is in fact ranok) begins at around four a.m. (when the rooster crows for the third time), irrespective of the season and the exact time of sunrise, and continues till about noon. The Ukrainian idea of day (den) encompasses the time from noon till about six p.m., whereas evening hours are from six p.m. till about midnight. The night hours for a Ukrainian person are normally from about midnight till four a.m. For an American the concept of time is not as standard as for a Ukrainian.

Morning. The Ukrainian word ranok is translated into English as morning and the concept itself in a lot of ways is similar in both languages. However, it can generally be said that in American English morning begins at the time a person awakes and ends by noon or by lunchtime. In Ukrainian the time shortly before noon can be referred to as either ranok or den. The most significant difference between ranok and morning in the two 
languages lies in the fact that morning in English can also include the hours between midnight and four a.m., while the same period of time in Ukrainian is generally referred to as nich.

Day. The literal translation of den into English is day. However, the concept of day in English is not limited to daylight hours. It may also refer to twenty-four hour period, beginning at midnight and ending the following midnight. The word day can also mean a specific day or date or a time established by common use or law in reference to school, business or work. This can be illustrated by the following examples:

What day are you going to the library? (meaning what day of the week you are planning to carry out the activity of going to the library)

What day is her birthday? (meaning the month and date of her birthday)

The children's day at school begins at eight and ends at three thirty. (meaning the number of hours the children spend at school)

It should be noted that day is an unspecified concept outside the above mentioned, whereas the time, following the morning hours and referred to in Ukrainian as den, should be expressed in English with the help of the word afternoon, a word which deserves a closer look.

Afternoon in American English generally refers to the time from noon till the end of the working day, which is at about five p. m. However, it must be noted that the use of the word afternoon may extend to sunset or can also refer to the time that the temperatures break into cooler weather in the late spring months and through summer (Kovalskaya \& Ritchey, 2001: 29-30).

When translating the English phrase in the afternoon into Ukrainian, it is recommended to use the following three equivalents: pislia poludnia, pislia obidu and vden. The choice will be motivated by the focus of the speaker's intentions. If the speaker is using general time orientation, then the word vden is more suitable. However, if the speaker's focus is that of activities rather than time, preference is given to the word combination pislia obidu, for it centers not on a specific hour but rather on the concept of activity, such as meals, regardless of the occurrence of the activity itself. Americans tend to interpret pislia obidu as meaning right after lunch, and not "during the afternoon" (Visson, 2013: 90).

Evening. The concept of vechir may also be problematic when translated into English. In Ukrainian it means the time of day beginning from 6 p.m. until the midnight hour. Though the English word evening is an accepted translation of vechir, it encompasses not only time orientation but also activities orientation with the major emphasis being placed on the latter. In fact, the word evening in American English means the period of 
time from sunset or the evening meal to bedtime. This definition reflects the shape of the individual's lifestyle. For example, in the same family the children's evening may conclude at 8 p.m. when they are sent to bed while their parents' evening will continue until 11 p.m. when they go to bed, and after that hour the use of the word night is appropriate (Kovalskaya \& Ritchey, 2001: 31).

It should be noted that there are some words and set expressions in English that refer to the evening time period, yet do not contain the word evening, for example: last night, tonight. They are translated into Ukrainian with the help of the word vechir.

As it has been shown, the notions denoting time of day in English are more activities oriented while in Ukrainian the similar notions are more clock oriented. In this respect the Ukrainian word vechir is an exception because one of its meanings is a social gathering in the evening hours and it is found in such word combinations as literaturnyi vechir, tantsiuvalnyi vechir, vechir-zustrich, vechir klasychnoi muzyky, etc. While translating these word combinations into English one should be very careful. One should avoid the use of the word evening, as it is not appropriate here. Thus, literaturnyi vechir may be translated as literary meeting and tantsiuvalnyi vechir as a dance. As for vechir-zustrich, it may mean several things depending on the circumstances.

Night. The word nich in Ukrainian denotes the period of time between sunset and sunrise (Slovnyk ukrainskoi movy), thus overlapping the concepts of vechir and ranok. Yet the common usage of the word nich normally restricts this concept to the hours between midnight and 4 p.m.

For Ukrainian students of English the problem of translation occurs with the understanding of phrases such as

He spends every Saturday night at the bowling alley.

Every Friday night they play checkers.

The question in the students' minds is if the person in question is spending only the evening hours on an activity or engaging in that activity until sunrise. The best solution to this problem is to look at the context in which the word night is used. For example, in the first sentence of the examples given above, we can conclude that, since the bowling alley would close before sunrise, the activity must be set within specific time parameters and cannot possibly refer to the person bowling until dawn. In the second sentence the information of time is more difficult to perceive, since the activity involved is not dependent on outside influences such as business's working hours. In this case the students must depend on background information, which they know about the people and activities involved. Thus, the words night and nich basically correspond to each 
other at the most fundamental level, the Ukrainian word nich is more restricted to the hours between midnight and four o'clock, while the English word night can be used interchangeably with the word evening.

\section{CONCLUSIONS}

Time is regarded as a linear progression that is measured by hours and the calendar. It is not only measured scientifically, but also is perceived on personal and cultural levels. The phenomenon of time is so multifaceted and has such a great degree of abstraction that the concepts of time form different temporal subsystems in American and Ukrainian cultures. Time concepts are culture-specific. The structure of the concepts day and night in American and Ukrainian cultures does not coincide. In Ukrainian, we have a word doba for day and night. Day and night are conceptualized differently: the night in English is not only the night, but also the evening, and it actually lasts until midnight. The Ukrainian night lasts until four o'clock in the morning. Students need to be aware of these differences and take them into account to avoid translation problems and breakdowns in cross-cultural communication. Further study is necessary to reveal the relations between American and Ukrainian concepts of time and space and their verbal representation.

\section{SUMMARY}

In today's world, it is both valuable and necessary to be aware of intercultural differences. In a cross-cultural setting a lot of misunderstandings arise from differences in time perception across cultures. One of the most basic breakdowns in cross-cultural communication occurs in the concept of time. Though few would argue the number of hours in a day, conversation is hindered cross-culturally when the worldview concept of time differs. That is why the purpose of this paper is to present the analysis of American and Ukrainian concepts of time that can cause translation problems. The concepts of time are objectivized by words and word combinations which give us the possibility to research them. It is worth pointing out that specific cultural features have been found in all the identified time concepts. These concepts are crucial in choosing not only the use of a particular word but the cultural context in which it is used. Time concepts are culturally loaded, reflecting cultural experience, habits, and way of life. They may partially coincide or be in contrast across the two cultures. 


\section{REFERENCES}

1. Kovalskaya, L. \& Ritchey, E. (2001). Breakthroughs in Basic Breakdowns of Intercultural Communication. Maikop: Adygei State University.

2. Oxford Advanced Learner's Dictionary (7th ed.). (2005). Oxford: Oxford University Press.

3. Oxford Idioms Dictionary for Learners of English. (2003). Oxford: Oxford University Press.

4. Slovnyk ukrainskoi movy [Dictionary of the Ukrainian language]. Retrieved from http://sum.in.ua/

5. The Random House College Dictionary (Revised Ed.). (1988). New York: Random House, Inc.

6. Visson, L. (2013). Where Russians Go Wrong in Spoken English. Moscow: R. Valent.

Information about the authors:

Koliada E. K.

Professor, $\mathrm{PhD}$,

Lesya Ukrainka Volyn National University

13 Voli ave., Lutsk, Volyn region, 43025, Ukraine

Kalynovska I. Assistant Professor, PhD,

Lesya Ukrainka Volyn National University

13 Voli ave., Lutsk, Volyn region, 43025, Ukraine 